\title{
Ruxolitinib in Myelofibrosis and Polycythemia Vera
}

\author{
LEAH WOLFE, RPh, BCOP, MTM, BScPharm
}

From Hematology Oncology Center Inc. - Pharmacy, Elyria, Ohio

Author's disclosures of potential conflicts of interest are found at the end of this article.

Correspondence to: Leah Wolfe, RPh, BCOP, MTM, BScPharm, Hematology Oncology Center Inc, 41201 Schadden Road, Suite 2, Elyria, OH 44035. E-mail: leahwolfe@ymail.com

doi: 10.6004/jadpro.2016.7.4.6

(1) 2016 Harborside Press ${ }^{\circ}$

J Adv Pract Oncol 2016;7;:436-444

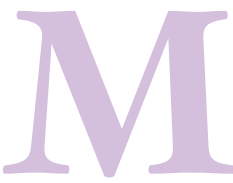

yelofibrosis (MF) and polycythemia vera (PV) are Philadelphia chromosome (BCRABL1)-negative subtypes of chronic myeloproliferative neoplasms (MPNs; Hudnall, 2012; Swaim, 2014). These rare hematologic malignancies share dysregulated signaling of Janus-associated kinasesignal transducer and activator of transcription (JAK-STAT) pathways essential for transduction of signals to the cell nucleus (Furqan, Mukhi, Lee, \& Liu, 2013). As a result, perpetually active signaling causes hyperproliferation of hematopoietic stem cells, extramedullary hematopoiesis, and excess release of cytokines, proteins that cause chronic inflammation and systemic itching (Lowery, 2013).

In 2005, researchers discovered the $J A K 2^{\text {V617F }}$ mutation, which is present in $50 \%$ to $60 \%$ of patients with MF and $95 \%$ of patients with PV (Stein et al., 2015). This significant finding helped pave the way for development of targeted therapies designed to inhibit overactive JAK signaling (Lowery, 2013). In 2011, the US Food and Drug Administration (FDA) approved ruxolitinib (Jakafi) as the first and only JAK inhibitor indicated for treatment of patients with intermediate- or high-risk MF, including primary $\mathrm{MF}$, post-PV MF, and post-essential thrombocythemia (ET) MF (Stenger, 2012). In 2014, the drug was approved for patients with PV who have inadequate response to or intolerance of the drug hydroxyurea (Inman, 2014).

In MF, unchecked JAK signaling leads to abnormal blood counts, bone marrow fibrosis, and excess production of inflammatory cytokines (Swaim, 2014). As hematopoiesis is forced to the spleen, splenomegaly causes feeling of early satiety and abdominal pain (Lowery, 2013). Quality of life is often significantly diminished by an interrelated symptom burden, which includes fatigue, bone pain, pruritus, and night sweats.

Risk stratification of MF at diagnosis is determined using the International Prognostic Scoring System (IPSS), which assigns points based on five risk factors: age > 65 years, hemoglobin $<10 \mathrm{~g} / \mathrm{dL}$, leukocyte count $>25 \times 10^{9} / \mathrm{L}$, circulating blasts $\geq 1 \%$, and presence of constitutional symptoms. Based on their score, patients are categorized as low-, intermediate-1, intermediate-2, or 
high-risk (Tefferi, 2013). Although it is possible for the disease to occur at any time, the median age at diagnosis is 65 years (Manea, 2014). Myelofibrosis can progress to acute myelogenous leukemia (Hudnall, 2012). The prevalence of MF in the United States is 4 to 6 per 100,000 population (Stein et al., 2015).

Typically diagnosed in older adults, PV is characterized by increased red cell production and may present elevated white cell and platelet counts (Hudnall, 2012). Patients experience increased blood viscosity and are at greater risk for thrombohemorrhagic events (Raedler, 2014b). Symptoms can include splenomegaly, fatigue, pruritus, and night sweats (Raedler, 2014a). The primary treatment goal is to minimize thrombosis. Therefore, patients are risk stratified based on age and thrombotic history (low to moderate risk: $\leq$ age 60 and no prior thrombosis; high risk: > age 60 and previous thrombosis; Tefferi \& Barbui, 2015).

Treatment includes low-dose aspirin and phlebotomy, with a target hematocrit value of $<45 \%$ to reduce thrombotic complications. In addition, hydroxyurea is often prescribed when patients are classified as high risk (Monga \& Devetten, 2010). Over a 10-year span, PV progresses to MF (considered secondary MF) and acute myelogenous leukemia at rates of approximately $10 \%$ and $<3 \%$, respectively (Harrison \& Vannucchi, 2012; Incyte, 2014b). Prevalence of PV in the United States is estimated to be 44 to 57 per 100,000 population (Stein et al., 2015).

\section{MECHANISM OF ACTION AND PHARMACOKINETICS}

Ruxolitinib, a kinase inhibitor, down-regulates overactive signaling of JAK1 and JAK2, which are responsible for mediating signals of cytokines and growth factors necessary for hematopoiesis and immune function (see Figure 1). Though there is some overlap, JAK1 plays a role in mediating several proinflammatory cytokines, whereas JAK2 is primarily responsible for hematopoietic growth factors (Swaim, 2014).

Ruxolitinib is rapidly absorbed, achieving peak concentration within 1 to 2 hours of dosing, with bioavailability of at least 95\% (Swaim, 2014). The drug has a volume of distribution

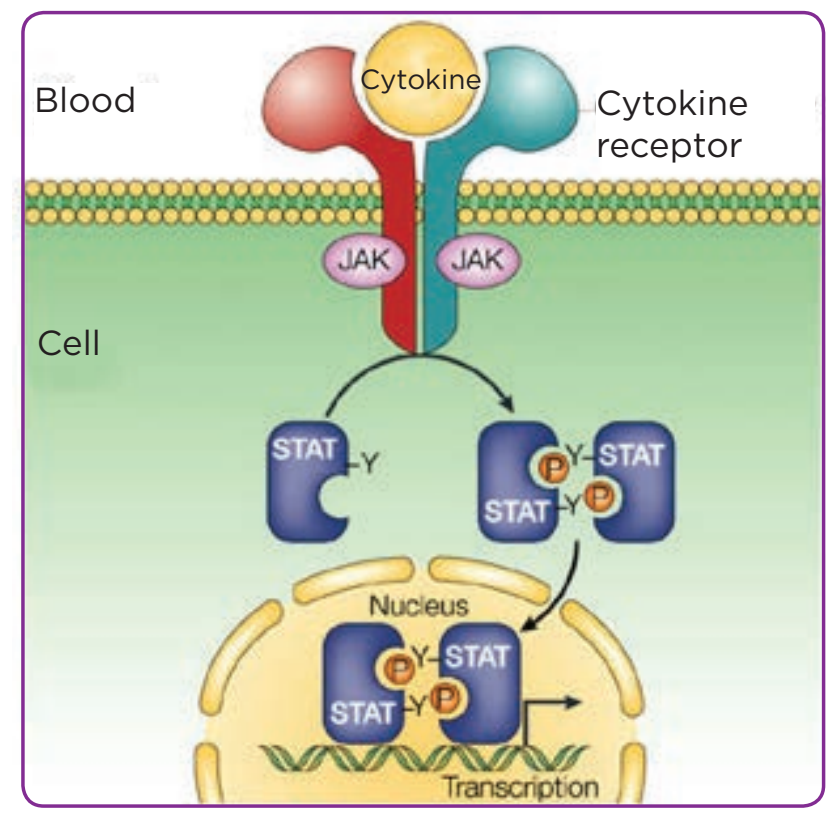

Figure 1. Overactive JAK-STAT pathway signaling: Mechanism of disease. JAKs are intracellular tyrosine kinases that relay extracellular signals via type I cytokine receptors (e.g., erythropoietin and thrombopoietin receptors in hematopoietic cells) to stimulate cell proliferation, differentiation, and survival as well as the production of proinflammatory cytokines. Adapted from The University of Texas MD Anderson Cancer Center (2015).

of 72-75 L and is protein bound. Ruxolitinib is metabolized by the liver via CYP3A4 and eliminated primarily by the kidneys (74\%). The mean elimination half-life is approximately 3 hours (5.8 hours for ruxolitinib and metabolites; Incyte Corporation, 2014a).

\section{CLINICAL TRIALS Myelofibrosis: COMFORT-I and COMFORT-II}

Ruxolitinib for intermediate-2 and high-risk MF was evaluated in two phase III clinical trials. COMFORT-I enrolled 309 patients in a doubleblind, randomized, placebo-controlled study. Median age was 68 years, and median baseline spleen volumes were 2,598 $\mathrm{cm}^{3}$ (ruxolitinib) and 2,566 $\mathrm{cm}^{3}$ (placebo; normal is $\leq 300 \mathrm{~cm}^{3}$ ). The primary endpoint was proportion of patients who achieved $\geq 35 \%$ reduction in spleen volume by week 24 . Secondary endpoints were durability of response, reduction in total symptom score, and overall survival (Verstovsek et al., 2012). 


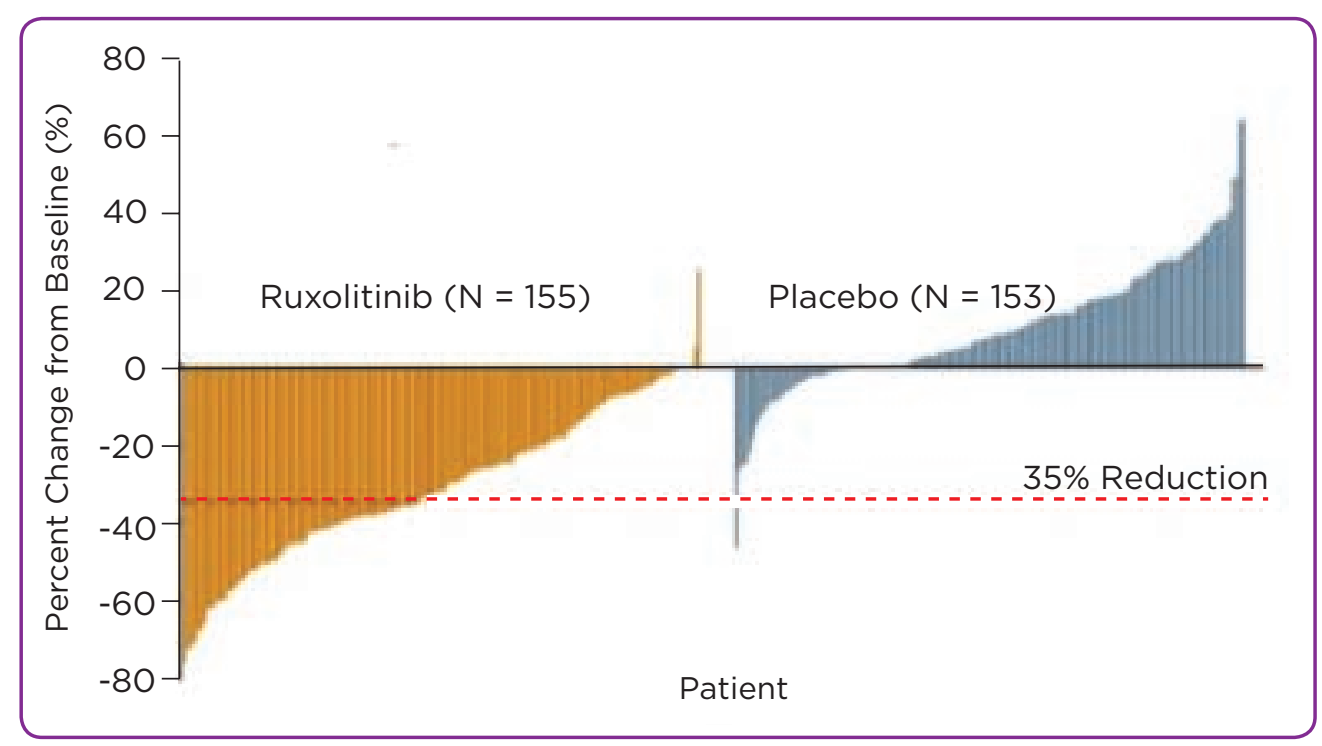

Figure 2. Percent change from baseline in spleen volume at week 24 or last observation for each patient in the study (COMFORT-I). Adapted from Verstovsek et al. (2012).

COMFORT-II was an open-label study of 219 patients who were randomized 2:1 to ruxolitinib or best available therapy (BAT) on a patient-by-patient basis. The median patient age was 66.5 years, and the median baseline spleen volumes were $2,208 \mathrm{~cm}^{3}$ (ruxolitinib) and 2,318 $\mathrm{cm}^{3}$ (BAT). The primary endpoint was proportion of patients achieving $\geq 35 \%$ reduction in spleen volume at week 48 . The secondary endpoints included proportion of patients achieving a $\geq 35 \%$ reduction in spleen volume at week 24 and overall survival (Harrison et al., 2012; Cervantes et al., 2013).

Both studies demonstrated that a statistically significant proportion of patients taking ruxolitinib achieved $\geq 35 \%$ reduction in spleen volume from baseline compared with placebo (COMFORT-I; see Figure 2) or BAT (COMFORT-II; Lowery, 2013). In the COMFORT-I trial, $46 \%$ of subjects taking ruxolitinib demonstrated $\geq 50 \%$ reduction in total symptom score vs. $5 \%$ receiving placebo (Verstovsek et al., 2012). Additionally, in the COMFORT-II trial, 28\% in the ruxolitinib group achieved $\geq 35 \%$ reduction in spleen volume vs. $0 \%$ for those receiving BAT at week 48. The corresponding results at week 24 were $32 \%$ and $0 \%$ (Harrison et al., 2012).

After 3 years of study, ruxolitinib demonstrated a measurable survival probability in both COMFORT-I and COMFORT-II, as shown in the
Kaplan-Meier curves in Figures 3 and 4 (Verstovsek et al., 2015a; Cervantes et al., 2013).

\section{Polycythemia Vera: RESPONSE Trial}

The RESPONSE trial was an international, open-label, multicenter phase III trial randomizing 1:1 ruxolitinib to BAT. Participants included 222 phlebotomy-dependent PV patients with splenomegaly who were resistant to or intolerant of hydroxyurea. The primary endpoint was twofold: achievement of hematocrit control and spleen volume reduction from baseline of $\geq 35 \%$ at week 32. Secondary endpoints included proportion of patients who achieved the primary endpoint and maintained their response at week 48 and proportion of patients who had complete hematologic remission (as defined by study protocol) at week 32 .

Results of primary and secondary endpoints are shown in Table 1. Additionally, $49 \%$ of the therapy group demonstrated at least a $50 \%$ reduction in total symptom score vs. $5 \%$ in the BAT group. Most patients receiving BAT crossed over to ruxolitinib at or immediately after week 32 (Vannucchi et al., 2015). As a result, the impact on overall survival could not be determined (Ignoffo, 2015).

\section{DOSING, MODIFICATIONS, AND SPECIAL POPULATIONS}

Ruxolitinib is available through a limited pharmacy network (Swaim, 2014). The oral 


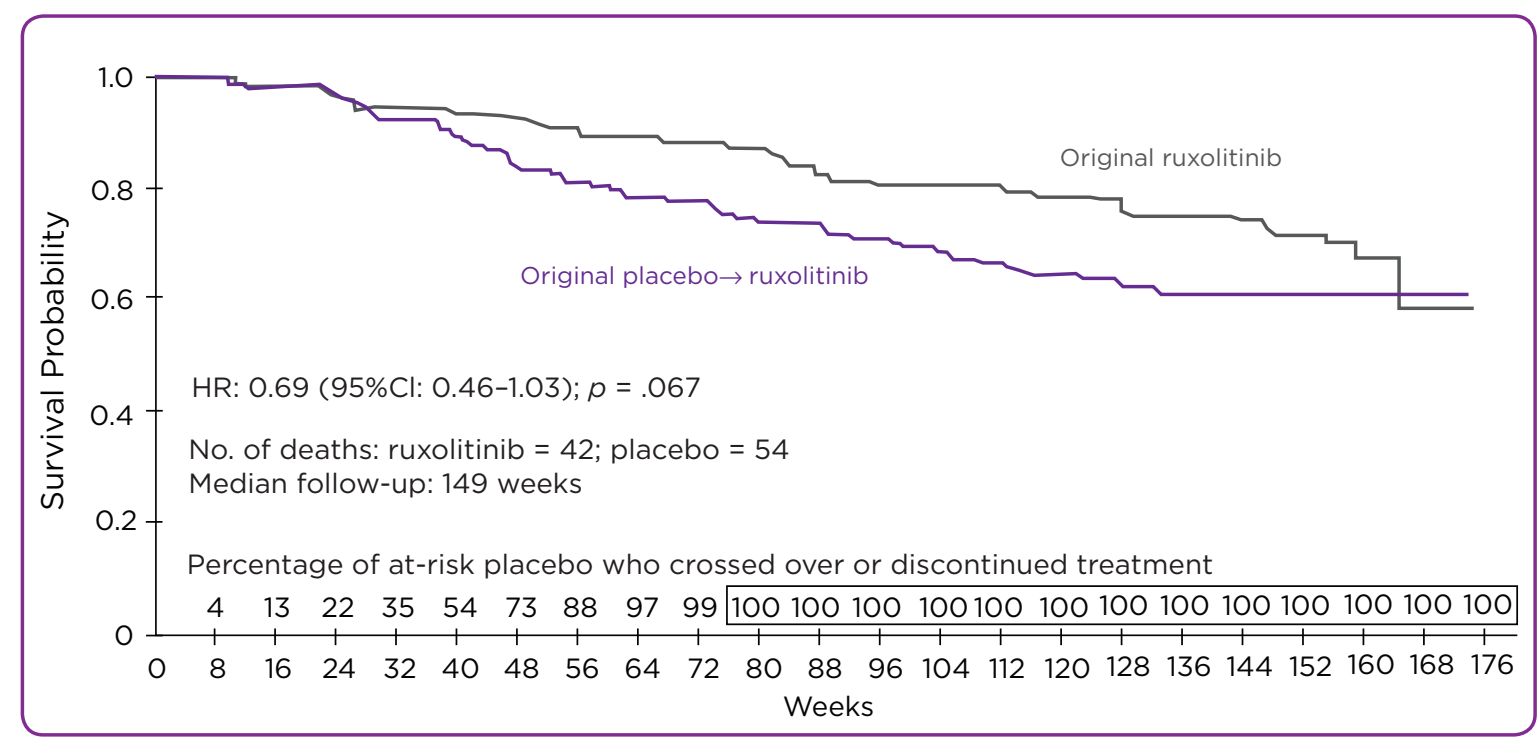

Figure 3. Overall survival: Kaplan-Meier curves by treatment group in COMFORT-I. HR = hazard ratio; $\mathrm{Cl}=$ confidence interval. Adapted from Verstovsek et al. (2015a).

medication is administered by tablet twice daily in adult and geriatric populations. It has five strengths $(5,10,15,20$, and $25 \mathrm{mg})$ and may be dissolved in $40 \mathrm{~mL}$ of water if administration via gastric tube ( 8 French or greater) is necessary (Lowery, 2013). Dosing is dependent on complete blood cell count (CBC) and platelet count, with modifications for patients with renal or hepatic impairment. Patients who miss a dose are directed to take the next dose at the regular time and must not take an additional dose. Ruxolitinib is stored at room temperature. It may be taken with or without food, but patients should be advised to avoid grapefruit juice. They should report all

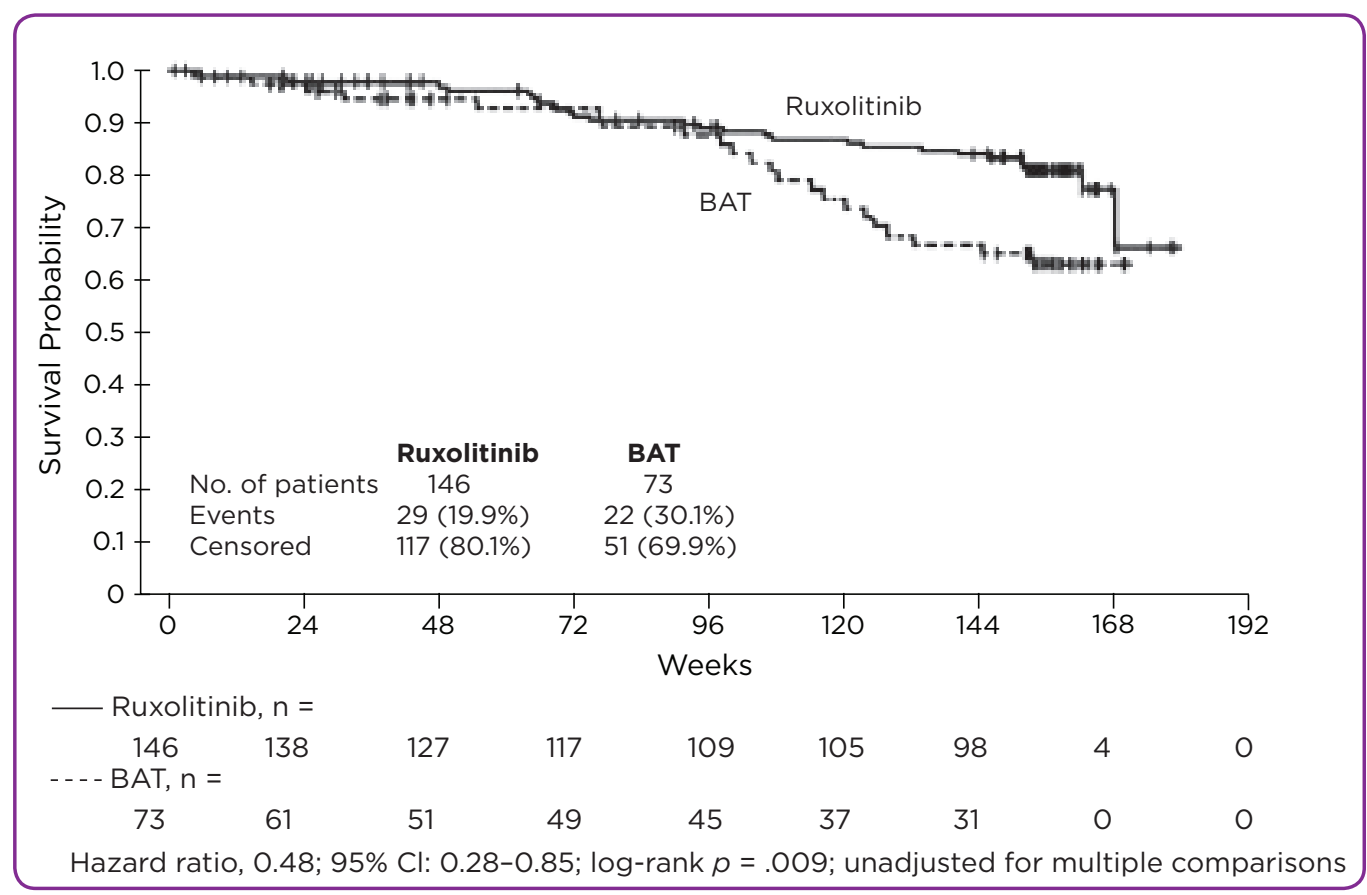

Figure 4. Overall survival: Kaplan-Meier curves by treatment group in COMFORT-II. BAT = best available treatment; $\mathrm{Cl}$ = confidence interval. Adapted from Cervantes et al. (2015). 


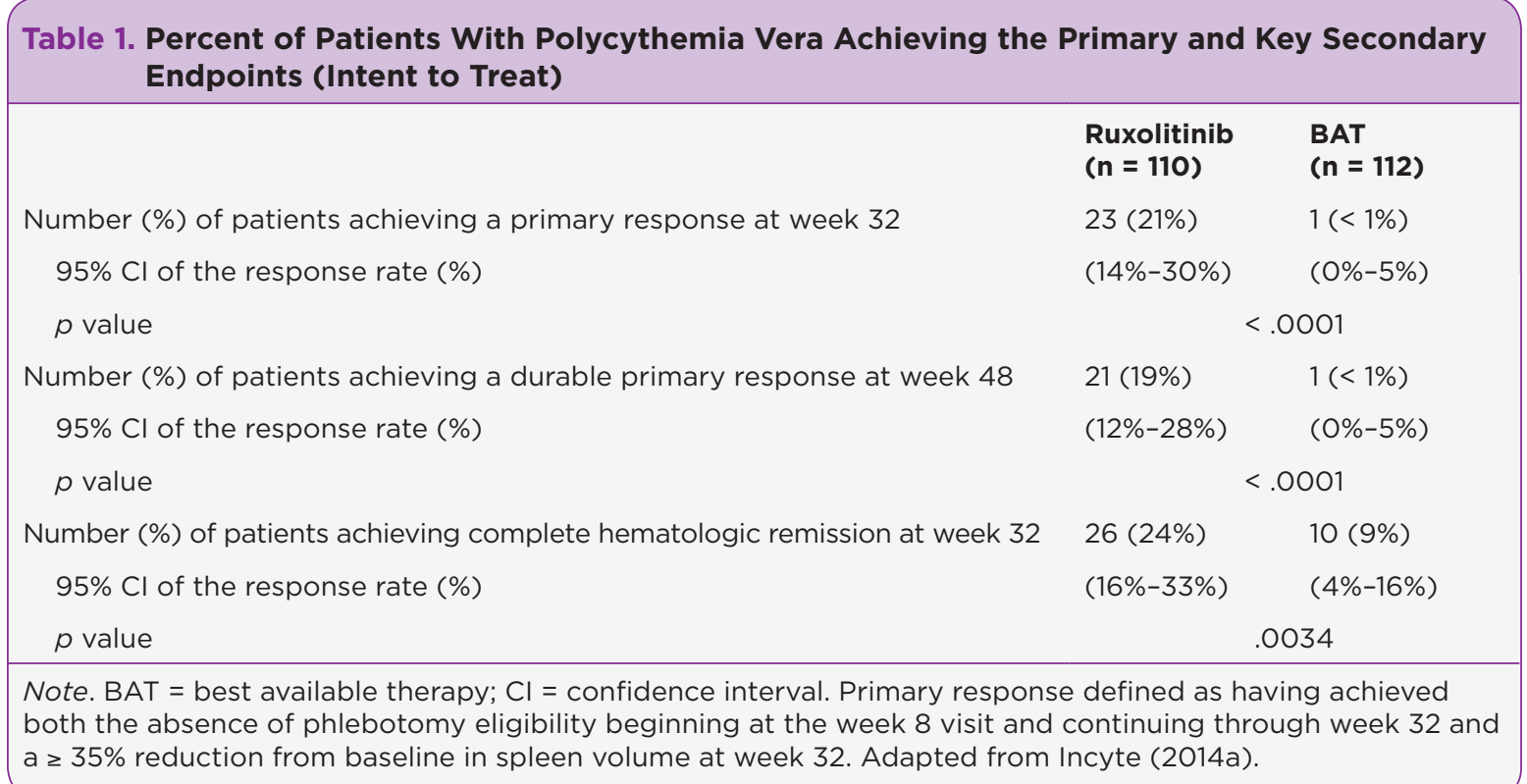

over-the-counter, herbal, or dietary supplements prior to the start of ruxolitinib. If patients require hospitalization, they should take their medication with them (Incyte Corporation, 2014a).

\section{Dosing in Intermediate- or High-Risk Myelofibrosis}

Dosing for patients with $\mathrm{MF}$ is based on platelets. A baseline CBC and platelet count is necessary prior to the start of treatment. Blood work should be repeated every 2 to 4 weeks until doses are stabilized and continued thereafter as clinically indicated (Incyte Corporation, 2014a; See Table 2).

Dosing modification may be indicated for patients with insufficient response or hematologic toxicity. Treatment should be interrupted in cases where bleeding requires medical intervention and may resume at the prior or lower

\section{Table 2. Ruxolitinib Starting Doses for Myelofibrosis}

\begin{tabular}{ll}
\hline Platelet count & Starting dose \\
$>200 \times 10^{9} / \mathrm{L}$ & $20 \mathrm{mg}$ orally twice daily \\
$100 \times 10^{9} / \mathrm{L}$ to $200 \times 10^{9} / \mathrm{L}$ & $15 \mathrm{mg}$ orally twice daily \\
$50 \times 10^{9} / \mathrm{L}$ to $<100 \times 10^{9} / \mathrm{L}$ & $5 \mathrm{mg}$ orally twice daily \\
\hline Note. Adapted from Incyte (2014a).
\end{tabular}

dose once the bleed has been resolved. Additionally, treatment should be interrupted if platelet count is $<50 \times 10^{9} / \mathrm{L}$ or absolute neutrophil count (ANC) is $<0.5 \times 10^{9} / \mathrm{L}$. Therapy may be resumed after the platelet count recovers to $>50$ $\times 10^{9} / \mathrm{L}$ and $\mathrm{ANC}>0.75 \times 10^{9} / \mathrm{L}$ (Incyte, 2014a; See Table 3).

\section{Dosing in Polycythemia Vera}

Before prescribing ruxolitinib for patients with PV, a baseline CBC and platelet count is necessary. For PV, the recommended starting dose of ruxolitinib is $10 \mathrm{mg} /$ twice daily and may be titrated based on safety and efficacy. Bloodwork should be repeated every 2 to 4 weeks until doses are stabilized and thereafter as clinically indicated. Dose reductions should be considered for hemoglobin and platelet count decrease (Incyte Corporation, 2014a; See Table 4).

\section{Treatment Interruption and Restarting}

Treatment should be interrupted for hemoglobin $(\mathrm{Hb})<8 \mathrm{~g} / \mathrm{dL}$, platelet count $<50 \times 10^{9} / \mathrm{L}$, or ANC $<1.0 \times 10^{9} / \mathrm{L}$. After hematologic levels recover, doses may be restarted as follows, using the most severe category of a patient's hemoglobin, platelet count, or ANC abnormality to determine the maximum restarting dose (Incyte Corporation, 2014a; See Table 5). 


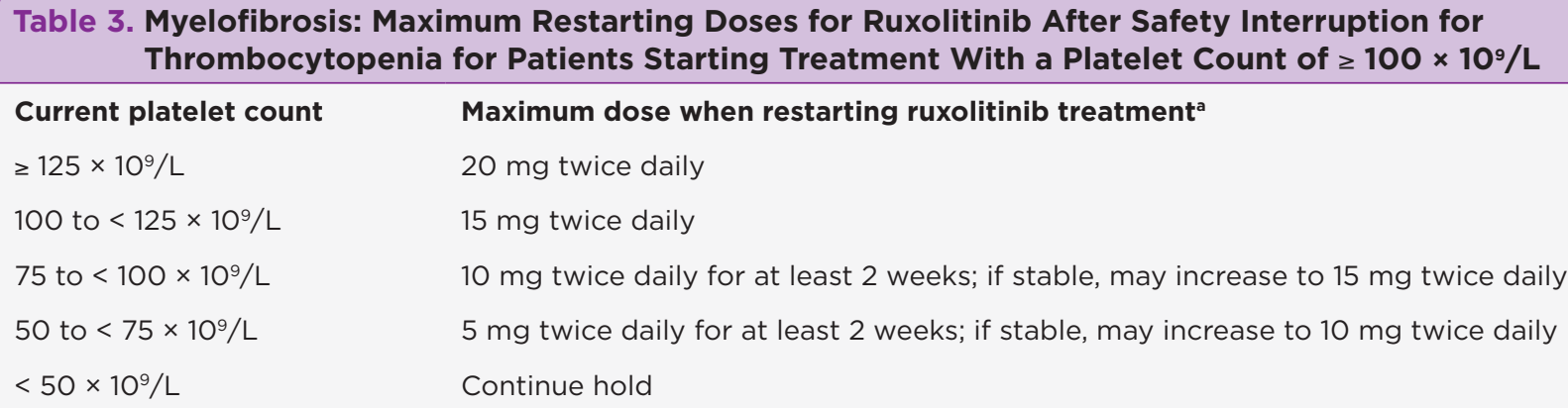

Note. a Maximum doses are displayed. When restarting treatment, begin with a dose at least 5 mg twice daily below the dose at interruption. Adapted from Incyte (2014a).

In both MF and PV, for complete information on dose modifications, as well as dosing for patients with renal or hepatic impairment, practitioners should refer to the full prescribing information available at http://www.jakafi.com/pdf/ prescribing-information.pdf.

\section{Drug Interactions and Special Populations}

There are no contraindications for ruxolitinib. Dose modification may be indicated when it is prescribed concomitantly with CYP3A4 inhibitors or inducers and/or fluconazole doses of less than or equal to $200 \mathrm{mg}$ daily. Avoid the use of fluconazole doses greater than $200 \mathrm{mg}$ daily concomitantly with ruxolitinib. Check drug interactions before prescribing. Ruxolitinib is a Category $\mathrm{C}$ drug in pregnancy, should not be taken by nursing mothers, and has not been studied in pediatrics. Patients with renal impairment on dialysis should be advised to take their dose after dialysis. Ruxolitinib should be avoided in pa- tients with end-stage renal disease who are not on dialysis (Incyte Corporation, 2014a).

\section{WARNINGS AND PRECAUTIONS}

Treatment may cause thrombocytopenia, anemia, and neutropenia, which are often managed by dose modification and/or blood transfusion (Lowery, 2013). Monitor CBC levels throughout treatment and advise patients to report bleeding or bruising. Ruxolitinib may increase the risk of nonmelanoma skin cancers. Patients should be advised to monitor skin changes (Incyte Corporation, 2014a).

Delay the start of ruxolitinib for patients with active infection. Patients should be monitored for and educated about tuberculosis, progressive multifocal leukoencephalopathy, and herpes zoster. Patients should report potential signs of infection, including chills, aches, fever, nausea/vomiting, or skin rash/blisters (Incyte Corporation, 2014a).

\section{Table 4. Polycythemia Vera: Dose Reductions}

\begin{tabular}{ll} 
Hemoglobin and/or platelet count & Dosing recommendations \\
Hemoglobin $\geq 12 \mathrm{~g} / \mathrm{dL}$ AND platelet count $\geq 100 \times 10^{9} / \mathrm{L}$ & No change required \\
$\begin{array}{l}\text { Hemoglobin } 10 \text { to }<12 \mathrm{~g} / \mathrm{dL} \text { AND platelet count } \\
75 \text { to }<100 \times 10^{9} / \mathrm{L}\end{array}$ & $\begin{array}{l}\text { Dose reductions should be considered with the } \\
\text { goal of avoiding dose interruptions for anemia and } \\
\text { thrombocytopenia }\end{array}$ \\
$\begin{array}{l}\text { Hemoglobin } 8 \text { to }<10 \mathrm{~g} / \mathrm{dL} \text { OR platelet count } \\
50 \text { to }<75 \times 10^{9} / \mathrm{L}\end{array}$ & $\begin{array}{l}\text { Reduce dose by } 5 \text { mg twice daily } \\
\text { For patients on } 5 \mathrm{mg} \text { twice daily, decrease the dose to } 5\end{array}$ \\
$\begin{array}{l}\text { Hemoglobin }<8 \mathrm{~g} / \mathrm{dL} \text { OR platelet count } \\
<50 \times 10^{9} / \mathrm{L}\end{array}$ & mg once daily \\
\hline Note. Adapted from Incyte (2014a). & \\
\hline
\end{tabular}




\section{Table 5. Polycythemia Vera: Restarting Doses for Ruxolitinib After Safety Interruption for Hematologic Parameter(s) \\ Hemoglobin, platelet count, or ANC \\ Hemoglobin $<8 \mathrm{~g} / \mathrm{dL}$ OR platelet count \\ $<50 \times 10^{9} /$ L OR ANC $<1 \times 10^{9} /$ L \\ Hemoglobin 8 to $<10 \mathrm{~g} / \mathrm{dL}$ OR platelet count \\ 50 to $<75 \times 10^{9} / \mathrm{L}$ OR ANC 1 to $<1.5 \times 10^{9} / \mathrm{L}$ \\ Hemoglobin 10 to $<12 \mathrm{~g} / \mathrm{dL}$ OR platelet count \\ 75 to $<100 \times 10^{9} /$ L OR ANC 1.5 to $<2 \times 10^{9} / \mathrm{L}$ \\ Hemoglobin $\geq$ to $12 \mathrm{~g} / \mathrm{dL}$ OR platelet count \\ $\geq 100 \times 10^{\%} / \mathrm{L}$ OR ANC $\geq$ to $2 \times 10^{9} / \mathrm{L}$ \\ Maximum restarting dose \\ Continue hold \\ $5 \mathrm{mg}$ twice daily or no more than $5 \mathrm{mg}$ twice daily less than the dose that resulted in dose interruption \\ $10 \mathrm{mg}$ twice daily or no more than $5 \mathrm{mg}$ twice daily less than the dose that resulted in dose interruption \\ $15 \mathrm{mg}$ twice daily or no more than $5 \mathrm{mg}$ twice daily less than the dose that resulted in dose interruption}

Note. Use the most severe category of a patient's hemoglobin, platelet count, or ANC (absolute neutrophil count)

abnormality to determine the corresponding maximum restarting dose. Adapted from Incyte (2014a).

\section{Adverse Reactions, Treatment Discontinuation, and Symptom Exacerbation}

During investigational trials, the most prevalent hematologic adverse effects for MF patients were thrombocytopenia and anemia, both related to dosing. The most common nonhematologic symptoms reported by COMFORT-I ruxolitinib patients were ecchymosis, dizziness, and headache; COMFORT-II ruxolitinib patients most frequently experienced diarrhea and abdominal pain (Harrison et al., 2012; Verstovsek et al., 2012).

Ruxolitinib was generally well tolerated by patients in the RESPONSE trial. At a median follow-up of 111 weeks, $83 \%$ of patients were still receiving treatment (Verstovsek et al., 2015b). The most common adverse reactions were anemia and thrombocytopenia (Ignoffo, 2015). Additionally, $>10 \%$ of patients reported headache, diarrhea, fatigue, pruritus, dizziness, muscle spasm, dyspnea, and/or abdominal pain (Vannucchi et al., 2015).

Reasons for discontinuation of treatment have included loss/lack of response, disease progression, toxicity, and patient or physician choice. Patients who stop ruxolitinib may experience an acute relapse of symptoms and splenomegaly, sometimes requiring emergency intervention (Tefferi \& Pardanani, 2011). Prescribers should caution against interruption or discontinuation of ruxolitinib without medical consultation. Except in cases of thrombocytopenia or neutropenia, doses should be gradually tapered (Swaim, 2014).

\section{IMPLICATIONS FOR ADVANCED PRACTITIONERS}

Myelofibrosis and polycythemia vera are rare clonal disorders of hematopoietic stem cells characterized by varied pathogenesis, debilitating symptom burden, and high mortality rates (Harrison \& Vannucchi, 2012). Ruxolitinib demonstrates a noteworthy evolution in treatment options by offering patients the hope of living longer and experiencing significant improvement in quality of life. Currently, National Comprehensive Cancer Network Guidelines for MPNs are in the planning stage (Stein, O’Brien, Greenberg, \& Mesa, 2015). Advanced practitioners in oncology are part of a crucial team, along with oncologists, hematologists, pharmacists, and physician assistants, ensuring that patients receive the monitoring, counseling, and support necessary to achieve optimal medication adherence and symptom management throughout treatment.

\section{Acknowledgments}

The author would like to acknowledge Kelley Gray, MA, BS, for writing and editing support throughout the production of this manuscript.

\section{Disclosure}

Ms. Wolfe owns one share of Incyte stock through a mutual fund. 


\section{References}

Cervantes, F., Vannucchi, A. M., Kiladjian, J. J., Al-Ali, H. K., Sirulnik, A., Stalbovskaya, V.,...Gisslinger, H. (2013). Three-year efficacy, safety, and survival findings from COMFORT-II, a phase 3 study comparing ruxolitinib with best available therapy for myelofibrosis. Blood, 122(25), 4047-4053. http://dx.doi. org/10.1182/blood-2013-02-485888

Furqan, M., Mukhi, N., Lee, B., \& Liu, D. (2013). Dysregulation of JAK-STAT pathway in hematological malignancies and JAK inhibitors for clinical application. Biomarker Research, 1(5). http://dx.doi. org/10.1186/2050-7771-1-5

Harrison, C, Kiladjian, J-J., Al-Ali, H. K., Gisslinger, H., Waltzman, R., Stalbovskaya, V....Barosi, G. (2012). JAK inhibition with ruxolitinib versus best available therapy for myelofibrosis. New England Journal of Medicine, 366(9), 787-798. http://dx.doi.org/10.1056/ NEJMoal110556

Harrison, C., \& Vannucchi, A. M. (2012). Ruxolitinib: A potent and selective janus kinase 1 and 2 inhibitor in patients with myelofibrosis: An update for clinicians. Therapeutic Advances in Hematology, 3(6), 341-354. http://dx.doi.org/10.1177/2040620712459746

Hudnall, S. D. (2012). Hematology: A pathophysiologic approach. Philadelphia, PA: Mosby.

Ignoffo, R. J. (2015). Concise reviews of studies relevant to hematology oncology pharmacy. Journal of Hematology Oncology Pharmacy, 5(2), 48-50.

Incyte Corporation. (2014a). Jakafi (ruxolitinib) package insert. Retrieved from http://www.jakafi.com/pdf/ prescribing-information.pdf

Incyte Corporation. (2014b). Polycythemia vera progression. Retrieved from http://www.mpnconnect.com/ polycythemia-vera.aspx

Inman, S. (2014). Jakafi approved for polycythemia vera. Retrieved from http://www.curetoday.com/articles/ Jakafi-Approved-for-Polycythemia-Vera

Lowery, E. W. (2013). Ruxolitinib: A new treatment for myelofibrosis. Clinical Journal of Oncology Nursing, 17(3), 312-318. http://dx.doi.org/10.1188/13.CJON.312-318

Manea, P. J. (2014). Optimizing the management of patients with myelofibrosis. Clinical Journal of Oncology Nursing, 18(3), 330-337. http://dx.doi.org/10.1188/14.CJON.330-337

Monga, M., \& Devetten, M. P. (2010). Chronic myeloproliferative diseases. In J. Abraham et al. (Ed.), The Bethesda Handbook of Clinical Oncology (3rd ed.). Philadelphia, PA: Lippincott Williams \& Wilkins.

Raedler, L. A. (2014a). Diagnosis and management of polycythemia vera: Proceedings from a multidisciplinary round table. Journal of Hematology Oncology Pharmacy, 4(4), S36-S47.

Raedler, L. A. (2014b). Thromboembolic events in myeloproliferative neoplasms: Assessing risk and optimizing value-based care. Journal of Hematology Oncology Pharmacy, 4(4), S68-S76.

Stein, B. L., Gotlib, J., Arcasoy, M., Nguyen, M. H., Shah, N., Moliterno, A.,...Mesa, R. A. (2015). Historical views, conventional approaches, and evolving management strategies for myeloproliferative neoplasms. Journal of the National Comprehensive Cancer Network, 13(4), 424-434.

Stein, B. L., O’Brien, S., Greenberg, P., \& Mesa, R. A. (2015). The need for United States-based guidelines for myeloproliferative neoplasms. Journal of the National Comprehensive Cancer Network, 13(5), 607-609.

Stenger, M. (2012). Ruxolitinib: Novel drug for myelofibrosis. Retrieved from http://www.ascopost.com/issues/november-15-2012/ruxolitinib-novel-drug-formyelofibrosis.aspx

Swaim, S. J. (2014). Ruxolitinib for the treatment of primary myelofibrosis. American Society of Health-System Pharmacists, 71, 453-462. http://dx.doi.org/10.2146/ ajhp120602

Tefferi, A. (2013). Primary myelofibrosis: 2013 update on diagnosis, risk-stratification, and management. American Journal of Hematology, 88(2), 141-150. http:// dx.doi.org/10.10021/ajh.23384

Tefferi, A., \& Barbui, T. (2015). Polycythemia vera and essential thrombocythemia: 2015 update on diagnosis, risk-stratification and management. American Journal of Hematology, 90(2), 162-173. http://dx.doi. org/10.1002/ajh.23895

Tefferi, A., \& Pardanani, A. (2011). Serious adverse events during ruxolitinib treatment discontinuation in patients with myelofibrosis. Mayo Clinic Proceedings, 86(12), 1188-1191. http://dx.doi.org/10.4065/ mcp. 2011.0518

University of Texas MD Anderson Cancer Center. (2015). Current research. Retrieved from http://www.mdanderson.org/education-and-research/departmentsprograms-and-labs/programs-centers-institutes/ mpn-clinical-research-center/current-research/index.html

Vannucchi, A. M., Kiladjian, J-J., Griesshammer, M., Masszi, T., Durrant, S., Passamonti, F.,...Verstovsek, S. (2015). Ruxolitinib versus standard therapy for the treatment of polycythemia vera. New England Journal of Medicine, 372(5), 426-435. http://dx.doi. org/10.1056/NEJMoa1409002

Verstovsek, S., Mesa, R. A., Gotlib, J., Levy, R. S., Gupta, V., DiPersio, J. F.,...Kantarjian, H. M. (2012). A doubleblind, placebo-controlled trial of ruxolitinib for myelofibrosis. New England Journal of Medicine, 366(9), 799-807. http://dx.doi.org/10.1056/NEJMoal110557

Verstovsek, S., Mesa, R. A., Gotlib, J., Levy, R. S., Gupta, V., DiPersio, J. F.,...Kantarjian, H. (2015a). Efficacy, safety, and survival with ruxolitinib in patients with myelofibrosis: Results of a median 3-year follow-up of COMFORT-I. Haematologica, 100(4), 479-488. http:// dx.doi.org/10.3324/haematol.2014.115840

Verstovsek, S., Vannucchi, A. M., Griesshammer, M., Masszi, T., Durrant, S., Passamonti, F.,...Kiladjian, J-J. (2015b). Ruxolitinib in polycythemia vera: Follow-up from the RESPONSE trial [Abstract 7087]. Journal of Clinical Oncology, 33. 